\title{
Stress, social support, and stopping smoking after myocardial infarction in England
}

\author{
Darren C Greenwood, Kenneth R Muir, Christopher J Packham, Richard J Madeley
}

\begin{abstract}
Study objective - To examine the effect on mortality of stopping smoking after myocardial infarction and the psychosocial factors that influence the decision to stop. Design - Analysis of smokers in a large prospective study. Self completed questionnaires provided information on psychosocial factors.

Setting - Coronary care units at six English hospitals participating in a multicentre clinical trial.

Subjects - These comprised consenting myocardial infarction survivors who had been identified as smokers and who completed questionnaires within seven days of infarct at six hospitals participating in the Anglo-Scandinavian study of early thrombolysis. The 532 patients identified have been followed for over five and a half years. The main outcome measure was five year all cause mortality.
\end{abstract}

Main results - Smokers who stopped within one month showed significantly reduced mortality compared with those who persisted, adjusting for other prognostic indicators (odds ratio $0 \cdot 56,95 \%$ confidence interval $0.33,0.98$ ). Overall, $74 \%$ stopped smoking. Being married, low life stress levels before infarct, and higher social class were associated with stopping smoking but the differentials were small. Of the clinical variables, a final diagnosis of definite myocardial infarction was associated with stopping smoking. All associations remained after multiple logistic regression.

Conclusions - Smoking cessation can halve the smokers' odds of dying after myocardial infarction and psychosocial factors play a small but important role in the important decision to stop smoking. Health professionals should continue to stress the importance of stopping smoking to all patients as there is little evidence to support specific directing of advice to relatively "stressed or "socially isolated" groups.

\section{(f Epidemiol Community Health 1995;49:583-587)}

There are two principal areas of research into the possible causes of myocardial infarction clinical variables and psychosocial variables. It was hoped that by considering factors such as behaviour pattern or personality type, stressful life events, level of education, social class, economic resources available, and social support much of our gap in knowledge about coronary heart disease aetiology would be filled. ${ }^{1-3}$ There have also been more specific studies of the influence of psychosocial factors on the prognosis after initial recovery from an acute myocardial infarction. ${ }^{24}$ Alongside the development of powerful drug treatments, psychosocial factors have been considered to be the direction for future research, to try to explain the different observed survival experiences of people with apparently similar clinical characteristics. ${ }^{35}$

We have recently shown that clinical variables form the core of statistical models describing survival of patients after acute myocardial infarction, ${ }^{67}$ with economic status an important extra psychosocial factor. We wanted to investigate the effect of stopping smoking among the smokers who had just suffered an infarct to determine whether we could identify certain groups who find it harder than most to follow anti-smoking advice. If these groups could be identified, health promotion could be directed at them. In this report, the effect on smokers of stopping smoking is investigated, and associations between psychosocial variables and the decision to stop are explored. Few studies have examined both the effects of stopping smoking on mortality and the psychosocial factors associated with the decision to stop in the same population, so that the influence of psychosocial variables on smoking and subsequent prognosis after myocardial infarction can be investigated.

\section{Methods}

Details of patients and methods used have been described previously. ${ }^{6}$ Patients included in the study were identified from the AngloScandinavian study of early thrombolysis (ASSET) ${ }^{89}$ All patients of either sex entering a coronary care unit at one of six hospitals involved in ASSET with clinically suspected acute myocardial infarction were considered for the study between November 1986 and February 1988. The six hospitals which agreed to take part were the University and City Hospitals, Nottingham, Royal United Hospital, Bath, Northampton General Hospital, York District Hospital, and the Princess Margaret Hospital, Swindon. Eligible patients were asked to complete a questionnaire to determine a range of psychosocial variables. The questions asked, and the construction of the psychosocial measures have already been described fully. ${ }^{6}$ In particular, social isolation was defined in the same way as in a directly equivalent US study ${ }^{4}$ - that is, in terms of lack of membership of a club, social or other organisation, church or 
synagogue, as well as the patient claiming to "never" or "hardly ever" visit friends or relatives in their homes, in the year preceding acute myocardial infarction. "High life stress" levels were defined as experience of a violent event and being very upset by it, or a divorce and being very upset by it, or a major financial difficulty, during the year before acute myocardial infarction. These were items considered relevant to British lifestyles taken from a five item life event scale used in the same US study. Smoking status before acute myocardial infarction was obtained from the questionnaire, while smoking status one month afterwards and the clinical data were obtained from ASSET. Smoking status beyond one month was not available for patients who failed to meet the ASSET inclusion criteria ( $57 \%$ of the patients in our study).

Patients have now been followed up between 5.6 and 6.9 years (median 6.3 years). The sole outcome measure was death from all causes. A shortlist of 25 personal, psychosocial, and clinical variables was constructed before the analysis took place. This contained the variables identified as being worth considering in a model to describe mortality after acute myocardial infarction, or variables of particular interest to the investigation (table 1). The $\chi^{2}$ statistic with Yates's correction (and where categories were ordered, $\chi^{2}$ test for trend) for the shortlisted variables were performed on the data, to show the univariate association with mortality of each variable. Multivariate modelling used logistic regression, because the proportional hazards assumption of Cox's regression ${ }^{10}$ was not met (the hazard ratio for patients stopping compared with those continuing decreased over time, perhaps due to a gradual improvement in the risk of a patient who stopped as it reverted to that of a nonsmoker).

A forwards stepwise selection procedure was used to select terms to be included in the model, so that extra variables were added only if they were significant at the $5 \%$ level or less. In this way the final model contained the best independent predictors of outcome. The modelling was performed using the EGRET computer package. ${ }^{11}$ All patients with data missing for any of the variables in the final model were excluded from that analysis.

Associations between the decision to stop smoking and the psychosocial and clinical variables were performed at a univariate level using $\chi^{2}$ tests and at a multivariate level using multiple logistic regression on the variables in table 1 (excluding the decision regarding smoking).

Table 1 Shortlist of variables considered for inclusion in the logistic regression modelling

\begin{tabular}{|c|c|c|c|}
\hline Personal & Clinical & & Psychosocial \\
\hline $\begin{array}{l}\text { Age group } \\
\text { Sex } \\
\text { Town/city } \\
\text { Smoking decision }\end{array}$ & $\begin{array}{l}\text { - Previous documented infarct } \\
\text { - History of diabetes mellitus } \\
\text { - History of hypertension } \\
\text { - History of angina } \\
\text { - On } \beta \text { blockers before acute } \\
\text { myocardial infarction } \\
\text { - Systolic blood pressure } \\
\text { <100 mmHg at admission } \\
\text { - Heart rate at admission } \\
\text { - Site of infarct } \\
\text { - ASSET treatment }\end{array}$ & $\begin{array}{l}\text { - Complications in hospital } \\
\text { Diagnosis on discharge } \\
\text { - Prescribed on discharge: } \\
\text { Digoxin } \\
\text { Anti-arrhythmics } \\
\text { Diuretic } \\
\beta \text { blockers }\end{array}$ & $\begin{array}{l}\text { Marital status } \\
\text { Social isolation } \\
\text { Life stress level } \\
\text { Car ownership } \\
\text { Social class } \\
\text { School leaving age }\end{array}$ \\
\hline
\end{tabular}

Table 2 Significant $(p<0 \cdot 01)$ univariate prognostic indicators in survivors of acute myocardial infarction, including the association between smoking cessation and mortality before adjustment for age and other factors

\begin{tabular}{|c|c|c|c|c|c|c|}
\hline Variable & Level & $\begin{array}{l}\text { Alive after } \\
5 y\end{array}$ & $\begin{array}{l}\text { Dead after } \\
5 y\end{array}$ & $\begin{array}{l}\% \\
\text { dead }\end{array}$ & $\begin{array}{l}\text { Relative } \\
\text { risk }\end{array}$ & $\begin{array}{l}95 \% \text { confidence } \\
\text { interval }\end{array}$ \\
\hline Age $(y)$ & $\begin{array}{c}<50 \\
50-54 \\
55-59 \\
60-64 \\
65-69 \\
70+\end{array}$ & $\begin{array}{r}152 \\
71 \\
89 \\
64 \\
41 \\
22\end{array}$ & $\begin{array}{r}9 \\
9 \\
21 \\
14 \\
19 \\
21\end{array}$ & $\begin{array}{r}6 \\
11 \\
19 \\
18 \\
32 \\
49\end{array}$ & $\begin{array}{l}1 \cdot 00 \\
2 \cdot 01 \\
3 \cdot 42 \\
3 \cdot 21 \\
5 \cdot 66 \\
8 \cdot 74\end{array}$ & $\begin{array}{l}- \\
0 \cdot 83,4 \cdot 87 \\
1 \cdot 63,7 \cdot 17 \\
1 \cdot 45,7 \cdot 09 \\
2 \cdot 71,11 \cdot 8 \\
4 \cdot 32,17 \cdot 7\end{array}$ \\
\hline $\begin{array}{l}\text { Previously documented } \\
\text { infarct }\end{array}$ & $\begin{array}{l}\text { No } \\
\text { Yes }\end{array}$ & $\begin{array}{r}382 \\
57\end{array}$ & $\begin{array}{l}69 \\
24\end{array}$ & $\begin{array}{l}15 \\
30\end{array}$ & $\begin{array}{l}1.00 \\
1.94\end{array}$ & $\overline{1 \cdot 30,} 2 \cdot 89$ \\
\hline History of diabetes mellitus & $\begin{array}{l}\text { No } \\
\text { Yes }\end{array}$ & $\begin{array}{r}431 \\
7\end{array}$ & $\begin{array}{l}85 \\
10\end{array}$ & $\begin{array}{l}17 \\
53\end{array}$ & $\begin{array}{l}1 \cdot 00 \\
3 \cdot 24\end{array}$ & $\overline{1.94,} \quad 5 \cdot 40$ \\
\hline History of angina & $\begin{array}{l}\text { No } \\
\text { Yes }\end{array}$ & $\begin{array}{l}304 \\
135\end{array}$ & $\begin{array}{l}43 \\
50\end{array}$ & $\begin{array}{l}12 \\
27\end{array}$ & $\begin{array}{l}1 \cdot 00 \\
2 \cdot 18\end{array}$ & $\overline{1.51}, 3.15$ \\
\hline Prescribed anti-arrythmics discharge & $\begin{array}{l}\text { No } \\
\text { Yes }\end{array}$ & $\begin{array}{r}433 \\
6\end{array}$ & $\begin{array}{r}87 \\
6\end{array}$ & $\begin{array}{l}17 \\
50\end{array}$ & $\begin{array}{l}1 \cdot 00 \\
2 \cdot 99\end{array}$ & $\overline{1.64}, \quad 5.43$ \\
\hline Prescribed diuretics on discharge & $\begin{array}{l}\text { No } \\
\text { Yes }\end{array}$ & $\begin{array}{r}361 \\
78\end{array}$ & $\begin{array}{l}59 \\
34\end{array}$ & $\begin{array}{l}14 \\
30\end{array}$ & $\begin{array}{l}1 \cdot 00 \\
2 \cdot 16\end{array}$ & $\overline{1 \cdot 50}, \quad 3 \cdot 12$ \\
\hline Car ownership & $\begin{array}{l}\text { Yes } \\
\text { No }\end{array}$ & $\begin{array}{l}323 \\
110\end{array}$ & $\begin{array}{l}50 \\
40\end{array}$ & $\begin{array}{l}13 \\
27\end{array}$ & $\begin{array}{l}1.00 \\
1.99\end{array}$ & $\overline{1 \cdot 37,} 2 \cdot 88$ \\
\hline School leaving age & $\begin{array}{l}11-14 \\
15-16 \\
17+\end{array}$ & $\begin{array}{r}164 \\
177 \\
37\end{array}$ & $\begin{array}{r}50 \\
17 \\
8\end{array}$ & $\begin{array}{r}23 \\
9 \\
18\end{array}$ & $\begin{array}{l}1.00 \\
0.38 \\
0.76\end{array}$ & $\begin{array}{ll}\overline{0.22}, & 0.63 \\
0.39, & 1.49\end{array}$ \\
\hline Giving up cigarette smoking & $\begin{array}{l}\text { No } \\
\text { Yes }\end{array}$ & $\begin{array}{l}107 \\
332\end{array}$ & $\begin{array}{l}29 \\
64\end{array}$ & $\begin{array}{l}21 \\
16\end{array}$ & $\begin{array}{l}1 \cdot 00 \\
0 \cdot 76\end{array}$ & $\overline{0.51}, \quad 1.12$ \\
\hline
\end{tabular}

Where the total number of subjects does not sum to 532 , this is attributable to missing data. 
Table 3 Variables included in the model of survival for 532 patients categorised as smokers at time of infarct. All variables made a statistically significant contribution at the $5 \%$ level or less

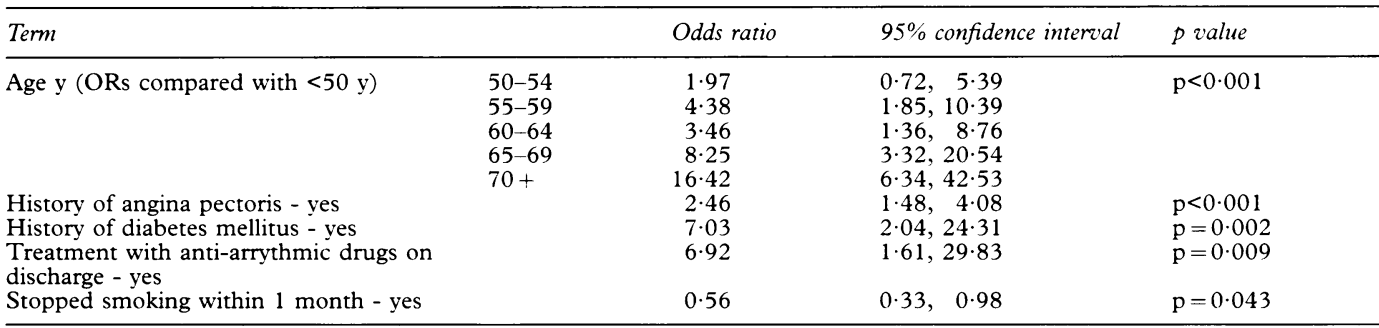

Table 4 Univariate analyses of psychosocial variables for smokers who had stopped by 1 month and for those who persisted with their habit

\begin{tabular}{|c|c|c|c|c|c|c|}
\hline \multirow[t]{2}{*}{ Psychosocial variable } & \multirow[t]{2}{*}{ Level } & \multicolumn{3}{|c|}{ Smoking decision at 1 month } & \multirow{2}{*}{$\begin{array}{l}\text { Relative risk } \\
\text { of stopping }\end{array}$} & \multirow{2}{*}{$\begin{array}{l}95 \% \text { confidence } \\
\text { interval }\end{array}$} \\
\hline & & Stop & Continue & $\%$ stopped & & \\
\hline \multirow[t]{2}{*}{ Marital status } & Unmarried & 67 & 34 & 66 & 1.00 & - \\
\hline & Married & 327 & 98 & 77 & $1 \cdot 16$ & $1 \cdot 00,1 \cdot 35$ \\
\hline \multirow{2}{*}{ Level of social isolation } & Low & 329 & 119 & 73 & 1.00 & - \\
\hline & High & 48 & 14 & 77 & 1.05 & $0.91,1.22$ \\
\hline \multirow[t]{2}{*}{ Life stress level } & Low & 264 & 82 & 76 & $1 \cdot 00$ & - \\
\hline & High & 88 & 43 & 67 & $0 \cdot 88$ & $0 \cdot 77,1 \cdot 01$ \\
\hline \multirow[t]{2}{*}{ Car ownership } & No car & 107 & 43 & 71 & $1 \cdot 00$ & - \\
\hline & Car & 281 & 92 & 75 & $1 \cdot 06$ & $0 \cdot 94,1 \cdot 19$ \\
\hline \multirow[t]{4}{*}{ Social class } & $\mathrm{I}+\mathrm{II}$ & 92 & 17 & 84 & $1 \cdot 00$ & - \\
\hline & IIINM & 57 & 18 & 76 & $0 \cdot 90$ & $0.78,1.05$ \\
\hline & IIIM & 125 & 56 & 69 & $0 \cdot 82$ & $0.72,0.93$ \\
\hline & $\mathrm{IV}+\mathrm{V}$ & 91 & 39 & 70 & $0 \cdot 83$ & $0.72,0.95$ \\
\hline \multirow[t]{3}{*}{ School leaving age (y) } & $11-14$ & 156 & 58 & 73 & 1.00 & - \\
\hline & $15-16$ & 149 & 45 & 77 & 1.05 & $0 \cdot 94,1 \cdot 18$ \\
\hline & $17+$ & 31 & 14 & 69 & 0.95 & $0 \cdot 76,1 \cdot 17$ \\
\hline
\end{tabular}

Where the total number of subjects does not sum to 532 , this is attributable to missing data

Results

This report is based on 532 patients who claimed to be smokers before acute myocardial infarction. A total of 3458 patients were eligible to receive a questionnaire. Of these, $1557 \mathrm{com}$ pleted the questionnaire, a response rate of $45 \%$. A further 274 patients were excluded as detailed elsewhere, ${ }^{6}$ leaving 1283 patients eligible for analysis (37\%). Out of these 1283 patients, 561 were smokers, 716 non-smokers and ex-smokers, and 6 of unknown smoking status. Of the 561 smokers, 19 had died within one month of acute myocardial infarction, 10 were alive but of unknown smoking status at one month, 396 claimed to have stopped within one month, and 136 remained smokers. Only the last two categories (totalling 532 patients) are included in this report.

Many of the clinical and psychosocial variables show a significant association with mortality without adjustment for other factors. Table 2 shows the percentage dead after five years for variables which were significant univariate prognostic indicators $(p<0.01$, since many variables are considered). Out of the 396 who stopped smoking, 64 had died within five years $(16 \%)$ and 29 of the 136 continuing smokers had died $(21 \%)$ (relative risk (RR) of death $=0 \cdot 76,95 \%$ confidence interval $(95 \%$ CI) $0.51,1.12, \mathrm{p}=0.2$ ). This result is also included in table 2 .

When known prognostic indicators were allowed for by the logistic regression modelling, only five variables from the original short list achieved a statistically significant independent contribution to the model $(\mathrm{p}<0 \cdot 05)$. The final model (table 3 ) included age, history of angina pectoris, history of diabetes, treatment with anti-arrythmic drugs on hospital discharge, and stopping smoking. The odds ratio (OR) for smokers who stopped compared with those who continued, adjusting for other terms in the model, was 0.56 (95\% CI $0.33,0.98)$. When only age was adjusted for the OR was almost identical to that in the full multivariate model (OR $=0.58,95 \%$ CI $0.34,0.99)$.

Overall, 396 out of 532 smokers (74\%) stopped smoking within one month. Similarly high cessation rates were found in all five cities: Nottingham 98 out of $133(74 \%)$; Bath 56 out of $66(85 \%)$; Northampton 87 out of 109 $(80 \%)$; York 59 out of $70(84 \%)$; and Swindon 96 out of $154(62 \%)$. For subjects in the study, $101(19 \%)$ were unmarried, $62(12 \%)$ had high levels of social isolation, and $131(25 \%)$ had a high level of life stress. The balance of psychosocial factors between smokers who stopped within one month and those who continued to smoke is shown in table 4. Factors associated with stopping were being married ( $R R$ of stopping $=1.16,95 \%$ CI $1.00,1.35, p=0.037)$, relatively low levels of stressful life events (RR of stopping $=1 \cdot 14,95 \%$ CI $0.99,1 \cdot 30, \mathrm{p}=$ 0.057 ; the association was marginally non-significant at the $5 \%$ level $)$, and social class $\left(\chi^{2}\right.$ test for trend, $\left.\chi^{2}=7 \cdot 8, p=0.005\right)$. Of those without definite myocardial infarctions (that is, probable myocardial infarction, possible myocardial infarction, or other), 59 of $318(19 \%)$ died within five years compared with 69 out of 197 (35\%) with definite myocardial infarctions diagnosed $(\mathrm{RR}$ of death $=1 \cdot 25,95 \%$ CI $1 \cdot 12$, $1 \cdot 41, \mathrm{p}<0.001): 46$ patients did not have diagnosis coded.

Multiple logistic regression on the variables in table 1 (excluding smoking decision) showed that stopping smoking was independently associated with poor diagnosis on hospital dis- 
Table 5 Independent predictors of stopping smoking from multiple logistic regression

\begin{tabular}{llll}
\hline Variable & Odds ratio & $95 \%$ confidence interval & $p$ value \\
\hline Diagnosis on discharge (definite infarct $v$ not) & 2.35 & $1 \cdot 50,3.68$ & $\mathrm{p}<0.001$ \\
Marital status (married $v$ not) & 1.77 & $1 \cdot 04,2.99$ & $\mathrm{p}=0.035$ \\
Life stress level (high $v$ low) & 0.60 & $0.37,0.96$ & $\mathrm{p}=0.034$ \\
Social class (linear trend; I+ II, IIINM, IIIM, IV +V) & 0.80 & $0.64,0.98$ & $\mathrm{p}=0.036$ \\
\hline
\end{tabular}

charge, being married, low life stress levels, and higher social class. These results are shown in table 5. Though statistically significant, confidence intervals are wide. For marital status, life stress, and social class, the intervals include both small effects and less modest ones.

\section{Discussion}

With the response rate of $45 \%$, any systematic difference between the responders and nonresponders in a way that might be associated with the decision to stop smoking would potentially lead to non-response bias. However, the response rate was not unfavourable given the patients' recent infarcts. As has been reported elsewhere, ${ }^{6}$ the non-responders were in general less well than the responders but the only large differences in the clinical details available for both responders and non-responders were the number of complications and the number of deaths within a month of acute myocardial infarction. The decision to stop smoking could differ systematically between the responders and non-responders because non-responders were more ill, and this might mean that our results are not as representative as would be optimal, although it is impossible to estimate the magnitude of any potential effect. Furthermore, it is unclear in what direction this could alter results. It has been suggested, however, that the benefit of stopping may be greatest in the lower risk patients. ${ }^{12} 13$ The multivariate analysis should go some way to adjusting for the effects of different baseline characteristics, and our results (smokers had just under twice the odds of dying compared with those who stopped) are comparable with those of Friedman et al who found that smokers were at a little more than twice the risk of patients who stopped smoking, ${ }^{14}$ Sparrow et al (RR after six years, 1.6), ${ }^{15}$ and Daly et al (RR of 1.7 for the first six years). ${ }^{12}$

The effect of stopping smoking after myocardial infarction reported here further demonstrates the importance of stopping smoking. The benefits of stopping smoking have been found, even though some patients who stopped within one month may have subsequently reverted to their habit after that time period, thereby diluting the observed benefits of stopping. These patients were still included with those who did stop smoking for analysis. Available data on smoking status beyond one month from those meeting stringent ASSET inclusion criteria suggested only about $15 \%$ of patients who decided to stop returned to smoking within a year.

The consistently high smoking cessation rate in all five cities suggests that this is applicable to survivors across England. The high percentage of people who decided to stop smoking within the first month after myocardial infarction has also been recorded in the US. ${ }^{16}$ In a recent study of nurse based intervention that began in the hospital and continued contact with the patient for six months found that $75 \%$ of patients reported that they were no longer smoking by three weeks. This decreased to $45 \%$, however, by one year follow up in the non-intervention arm. Fortunately in our study the available evidence points to very few smokers having relapsed.

In this study, being married was not found to influence overall mortality after allowance for other factors. Though it was associated with the important decision to stop smoking and confidence intervals are wide, the estimated association is only a modest one and two thirds of unmarried patients stopped smoking anyway. The measure of social support used (frequency of attending clubs and visiting friends) was not significantly associated with stopping smoking. This may be because the type of social support that was measured was intermittent, or it may be due to a difference in quality between social support from friends and that offered by a spouse. However, neither form of support showed an important association that would justify targeting health promotion advice to "socially isolated" patients or those with no spouse. For level of social isolation, the study had $71 \%$ power to detect an OR of 0.5 for socially isolated subjects (in the multivariate analysis). This dropped rapidly, however, for more modest effects. Low power could account for the statistically non-significant finding for social isolation. Other comparisons, however, had sufficient power to detect more modest effects.

Stressful life circumstances before acute myocardial infarction were also associated with continued smoking after acute myocardial infarction, in common with other studies investigating the effects of various measures of stress. ${ }^{17-19}$ Once again the size of this association was not great and was therefore of only limited clinical significance, although the confidence intervals are wide.

In addition to stress and marital status, social class was found to be associated with continued smoking, which is confirmed by previous reports. ${ }^{2021}$ This may reflect different reactions to medical advice (for example, groups IV and $\mathrm{V}$ may take less notice of such health advice or the advice may not be worded appropriately), different social support structures, or a greater likelihood of the spouse and friends who are relied on to provide support and encouragement being smokers themselves. Social class, however, is not amenable to intervention, which limits the practical importance of this association. Even if the differences could be attributed to reasons suggested above, even in 
social classes IV and V the smoking cessation rate was $70 \%$, and this rose only slightly to $84 \%$ in social classes I and II.

The decision to stop was strongly associated with a diagnosis of definite myocardial infarction as opposed to probable or possible myocardial infarction or other diagnosis. This might suggest that these patients were more motivated to stop smoking. The motivation may have come from the individual after being told their diagnosis or a clinician or general practitioner may have given strongly worded advice to stop. Either way, it would seem the motivation to stop may have come from a fuller understanding of the seriousness of the situation, and this should encourage clinicians and spouses to ensure the patient is aware of the full consequences of the decision to continue smoking after myocardial infarction. Likewise, this re-emphasises the necessity of the educational role of rehabilitation courses. It should be remembered that previous reports have suggested that stopping smoking may have most benefit in low risk patients. ${ }^{1213}$ This should encourage those who give advice on smoking after acute myocardial infarction not just to target patients perceived to be at higher risk because of a diagnosis of definite infarct, as might have happened to patients in this study. This also seems to explain why smoking cessation was not a statistically significant univariate predictor of survival, but when other prognostic factors were taken into account the association became significant.

Any role of psychosocial factors must be put into perspective, by recognising the dominant influence a patient's clinical status has on their prognosis, for example having a history of previous myocardial infarction or powerful drugs administered after acute myocardial infarction. Psychosocial factors may play a part in making changes to high risk lifestyles, such as deciding to give up smoking, but their role is not a major one and provides no evidence for the provision of advice directed at individuals identified on the basis of psychosocial wellbeing alone. Interventions to help patients give up smoking or to aid a patient's rehabilitation by tackling stress may not be easy to design and might not reduce smoking by any great amount.

The general practitioner is well placed to take advantage of the receptiveness of patients to health promotion while ill. It has been said that a general practitioner may persuade a patient to stop smoking but it is the social conditions they go home to which decide if the decision stands. ${ }^{22}$ This study shows that the home environment may play only a modest role.

This study has shown that stopping smoking greatly improves survival, and the high smoking cessation rate found is encouraging considering the importance of the decision. Certain psy- chosocial factors are associated with the decision to stop smoking but the strength of association is small. Highly "stressed" patients or those with no spouse may benefit only marginally from extra attention, and there is little evidence to support the strategy of especially targeting these groups in particular. Further work is required to identify methods of encouraging and helping all persistent smokers to give up following myocardial infarction.

We gratefully acknowledge the constructive comments on earlier drafts from the anonymous referee. We thank Dr Allan Skene and Mr Andrew Charlesworth from the Nottingham Clinical Trial Data Centre for access to the clinical data from the ASSET study, and Dr David Gray for advice on established prognostic indicators. We also thank the consultant physicians at the indicators. We also thank the consultant physicians at the
coronary care units involved, their staff and patients for their coronary care units involved, their staff and patients for their
cooperation. This study was supported by a grant from the British Heart Foundation.

1 Ruberman W. Psychosocial influences on mortality of patients with coronary heart disease. $\mathcal{F} A M A$ 1992;267: p59-60.

2 Wiklund I, Oden A, Sanne H, Ulvenstam G, Wilhelmsson $C$, Wilhelmsen L. Prognostic importance of somatic and psychosocial variables after a first myocardial infarction. Am $\mathfrak{f}$ Epidemiol 1988;128:786-95.

3 Badura B. Life-style and health: some remarks on different viewpoints. Soc Sci Med 1984;19:341-7.

4 Ruberman W, Weinblatt E, Goldberg JD, Chaudhary BS. Psychosocial influences on mortality after myocardial in farction. $N$ Engl $\mathcal{F}$ Med 1984;311:552-9.

5 Mitchell JRA. Hearts and minds. BMF 1984;289:1557-8.

6 Greenwood D, Packham C, Muir K, Madeley R. How do economic status and social support influence survival fter initial recovery from social support influence survival after Med 1995;40:639-47.

7 Jenkinson CM, Madeley RJ, Mitchell JRA, Turner ID. The influence of psychosocial factors on survival after myocardial infarction. Public Health 1993;107:305-17.

8 Wilcox RG, von der Lippe G, Olsson CG, Jensen G, Skene AM, Hampton JR. Trial of tissue plasminogen activator for mortality reduction in acute myocardial infarction. Anglo-Scandinavian study of early thrombolysis (ASSET). Lancet 1988;ii:525-30.

9 Wilcox RG, von der Lippe G, Olsson CG, Jensen G, Skene AM, Hampton JR. Effects of alteplase in acute myocardial infarction: 6-month results from the ASSET study. Lancet 1990;335:1175-8.

10 Cox DR. Regression models and life tables (with discussion). F $R$ Stat Soc B 1972;34:187-220.

11 Epidemiological graphics estimation and testing (EGRET). Seattle: Statistics and Epidemiology Research Corporation and Cytel Software Corporation, 1985-91.

12 Daly LE, Mulcahy R, Graham IM, Hickey N. Long term effect on mortality of stopping smoking after unstable effect on mortality of stopping smoking after unstable
angina and myocardial infarction. $B M \mathcal{F}$ 1983;287:324-6. 13 Salonen JT. Stopping smoking and long-term mortality after acute myocardial infarction. Br Heart f 1980;43:463-9.

14 Friedman GD, Petitti DB, Bawol RD, Siegelaub AB. Mortality in cigarette smokers and quitters. Effect of baseline differences. $N$ Engl f Med 1981;304:1407-10.

15 Sparrow D, Dawber TR, Colton T. The influence of cigarette smoking on prognosis after a first myocardial infarction. $\mathcal{F}$ Chron Dis 1978;31:425-32.

16 Taylor CB, Houston-Miller N, Killen JD, DeBush RF. Smoking cessation after acute myocardial infarction: effects of a nurse-managed intervention. Ann Intern Med 1990;113:118-23.

17 Glasgow RE, Klesges RC, Mizes JS, Pechacek TF. Quitting smoking: strategies used and variables associated with success in a stop-smoking contest. $\mathcal{f}$ Consult Clin Psychol 1985;53:905-12.

18 Curry S, Thompson B, Sexton M, Omenn GS. Psychosocial predictors of outcome in a worksite smoking cessation program. Am $\mathcal{f}$ Prev Med 1989;5:2-7.

19 Ockene JK, Nutall R, Benfari RC, Hurwitz I, Ockene IS A psychosocial model of smoking cessation and maintenance of cessation. Prev Med 1981;10:623-38.

20 Abrams DB, Biener L. Motivational characteristics of smokers at the workplace: A public health challenge. Prev Med 1992;21:679-87.

21 Wilcox NS, Prochaska JO, Velicer WF, DiClemente CC. Subject characteristics as predictors of self-change in Subject characteristics as predictors of
smoking. Addict Behav 1985;10:407-12.

22 Stott NCH. Addict Behav 1985;10:407-12. primary care consultation. $f R$ Coll Gen Pract 1979;29: primary 